\title{
BPC 157 prevents development of MCT-induced pulmonary hypertension and cor pulmonale in rats
}

\author{
Predrag Sikirić*, Mario Udovičić, Ivan Barišić, Diana Balenović, Sandra Uzun, Dean Strinić, \\ Martina Lovrić Benčić, Sven Seiwerth \\ University of Zagreb School of Medicine, Zagreb, Croatia
}

\begin{abstract}
Pentadecapeptide BPC 157 antagonises the incidence of a series of gastrointestinal lesions, it has a positive impact on the healing processes of various wounds, a proven angiogenic effect, protective effect on endothelium and it modulates synthesis of NO. BPC 157 furthermore reduces the duration of arrhythmias induced by ischemic-reperfusional injury in the isolated pig heart, and it also has an antihypertensive effect in the model of L-NAME-induced hypertension.

Monocrotaline (MCT) is a pyrrolizidine alkaloid, which given subcutaneously in the rat model of pulmonary hypertension on the day 1 ( $80 \mathrm{mg} / \mathrm{kg}$ body weight), selectively injures the vascular endothelium of the lung and induces pulmonary vasculitis, induces muscularization and hypertrophy of the

\section{Received: $24^{\text {th }}$ Apr 2014}

*Address for correspondence: Zavod za farmakologiju Medicinskog fakulteta Sveučilišta u Zagrebu, Šalata 11, HR-10000 Zagreb, Croatia.

Phone: +385-1-4566-833

E-mail: sikiric@mef.hr
\end{abstract}

media in pulmonary arteries, that lead to an increased vascular resistance and increased pulmonary arterial pressure. MCT-induced pulmonary hypertension is associated with the development of the compensated RV hypertrophy, which progresses to the failure within weeks.

In this study, when administered intraperitoneally from Days 1-29, BPC 157 inhibited the development of muscularization and hypertrophy of the media in pulmonary arteries, it prevented pulmonary hypertension and the right heart hypertrophy and failure. A corresponding efficacy profile was also noted for long-term peroral administration of BPC 157 in drinking water from Days 1-29. Moreover, the death rate significantly decreased in those animals treated with BPC 157.

We conclude that BPC 157 prevents development of MCTinduced pulmonary hypertension and cor pulmonale in rats.

KEYWORDS: pentadecapeptide BPC 157, monocrotaline, cor pulmonale, pulmonary hypertension, rats.

CITATION: Cardiol Croat. 2014;9(5-6):246.

\section{Literature}

1. Sikiric P, Seiwerth S, Rucman R, et al. Stable gastric pentadecapeptide BPC 157-NO-system relation. Curr Pharm Des. 2014;20(7):1126-35.

2. Sikiric P, Seiwerth S, Rucman R, et al. Focus on ulcerative colitis: stable gastric pentadecapeptide BPC 157. Curr Med Chem. 2012;19(1):126-32. 